\title{
AMOSTRAGEM DE POLUENTES GASOSOS E PARTICULADOS FINOS EMITIDOS PELA COMBUSTÃO DO BAGAÇO DA CANA-DE-AÇÚCAR
}

\author{
F. F. MARCONDES ${ }^{1}$, M. A. M. COSTA ${ }^{1}$, J. A. de CARVALHO. Jr² ${ }^{2}$ J. E. F. \\ CIELINSK $^{1}$ e A. P. SANTOS 1
}

${ }^{1}$ Universidade Estadual Paulista, Departamento de Engenharia Industrial Madeireira

2 Universidade Estadual Paulista, Departamento de Energia

E-mail para contato: fernanda.marcondes@grad.itapeva.unesp.br

\begin{abstract}
RESUMO - A produção brasileira de etanol com base na cana-de-açúcar é vista como a tecnologia de biocombustível mais eficiente atualmente. Entretanto, os impactos ambientais deste processo ainda não foram devidamente analisados. Este trabalho teve como objetivo a quantificação de poluentes gasosos gerados pela queima do bagaço de cana-de-açúcar, além da realização da análise química do referido combustível e a amostragem dos traços gasosos dos gases $\mathrm{CO}, \mathrm{CO}_{2}$ e $\mathrm{NO}_{\mathrm{X}}$ emitidos em tempo real de queima. As concentrações médias encontradas de $\mathrm{CO}, \mathrm{CO}_{2}$ e $\mathrm{NO}_{\mathrm{X}}$ foram, respectivamente, $122 \mathrm{ppm}, 0,59 \%$ e 14,3 ppm. Tanto o CO quanto o NOx tiveram seus limites estabelecidos pela legislação, não só do Brasil como de outros países, ultrapassados. Em relação ao $\mathrm{CO}_{2}$, ainda não há regulamentação para o mesmo. Este monitoramento das emissões provenientes da combustão da cana é importante para a tomada de decisões em termos científicos e políticos, afinal, o Brasil é alvo de inúmeras críticas ambientais.
\end{abstract}

\section{INTRODUÇÃO}

Biomassa é um termo empregado para todo o material orgânico que se origina a partir de plantas, tendo a madeira como principal representante. Do ponto de vista químico, é um material composto, constituído por uma mistura de holocelulose, lignina, extrativos, cinzas e matéria inorgânica, com a proporção e a estrutura química afetada pela variedade (Blasi, 2005).

Hoogwijk et al. (2002) apontaram que a biomassa é vista como uma fonte de energia interessante, podendo contribuir para o desenvolvimento sustentável. A energia da biomassa é viável do ponto de vista da segurança energética. Os recursos são muitas vezes disponíveis localmente e a conversão em vetores de energia alternativos é possível sem investimentos elevados. A biomassa é considerada a única fonte de carbono orgânico sustentável atualmente disponível sobre a terra e pode ser vista como a substituta ideal para o petróleo na produção de combustíveis, produtos químicos e materiais à base de carbono (Ruiz et al., 2012).

O sistema de produção de bioenergia geralmente consiste em duas etapas. Primeiro, a produção de biomassa e, em segundo lugar, pré-tratamento da biomassa e a conversão em produtos energéticos, por exemplo, calor, eletricidade, combustíveis gasosos e líquidos, como o etanol, metano e biodiesel. A cultura alimentar como a cana-de-açúcar é considerada uma 
fonte de energia positiva, pois requer baixas entradas de energia fóssil na produção de biomassa e de conversão. Além do açúcar como principal produto, bagaço e melaço também são importantes subprodutos da cana-de-açúcar. O bagaço é utilizado para gerar vapor e eletricidade para uso local e para exportação para a rede (Nguyen et al., 2009).

De acordo com Costa et al. (2010), o Brasil é o maior produtor mundial de cana-deaçúcar. Em 1961, o Brasil foi responsável por $85 \%$ da cana total produzida nos países do Mercosul e, desde então, aumentou para $97 \%$ devido aos avanços tecnológicos do Brasil em relação aos países restantes. A participação do Brasil na produção mundial de cana aumentou de $16 \%$ para $34 \%$ em 43 anos. A produção interna no mesmo período aumentou $647 \%$, e este aumento foi estimulado por políticas internas voltadas ao consumo de álcool como combustível. Segundo o Ministério da Agricultura, a produção de etanol com base na cana-deaçúcar conta com projeções positivas para os próximos anos, devidas principalmente, ao crescimento do consumo interno. A produção projetada para 2019 é de 58,8 bilhões de litros, mais que o dobro da registrada em 2008. O consumo interno está projetado em 50 bilhões de litros e as exportações em 8,8 bilhões. Esse salto na produção de etanol traz, como consequência, o drástico aumento das emissões atmosféricas geradas com a combustão da cana-de-açúcar.

Segundo Carvalho Jr. e Lacava (2003), a preocupação acerca da emissão de poluentes só se tornou relevante no cenário mundial a partir do início da década de 70 . Os poluentes atmosféricos possuem um grande volume por unidade de massa e, uma vez lançados na atmosfera, misturam-se com o ar e são levados pelas correntes de vento, em um movimento basicamente não controlável. Os autores também relatam que uma das maiores fontes de emissão de poluentes são os gases resultantes de dispositivos que aproveitam a energia térmica liberada pelas reações de combustão, como na queima de biomassa, por exemplo.

França et al. (2012) determinaram a emissão de alguns gases durante a queima de canade-açúcar. Os fatores de emissão de $\mathrm{CO}_{2}, \mathrm{CO}$ e $\mathrm{NOx}$ foram estimados a partir de medições contínuas das respectivas concentrações, realizadas em condições controladas no laboratório. Os valores médios amostrados para os fatores de emissão ( $\mathrm{g} / \mathrm{kg}$ de biomassa seca queimada) foram $1,303 \pm 218$ para o $\mathrm{CO}_{2}, 65 \pm 14$ para o $\mathrm{CO}$ e $1,5 \pm 0,4$ para NOx. Sabe-se que, a combustão da biomassa ocorre em três fases: ignição, chama e incandescência. Neste trabalho, concluiu-se que, durante a fase de chama, uma maior quantidade de compostos tais como $\mathrm{CO}_{2}$ e $\mathrm{NO}_{\mathrm{X}}$ foram gerados. Por outro lado, os compostos não completamente oxidados, tais como o CO, foram gerados em maior concentração na fase de incandescência.

Soares Neto et al. (2011), por sua vez, determinaram a emissão de poluentes atmosféricos provenientes da combustão de amostras de biomassa da Amazônia, as quais representavam espécies florestais nativas, com teor de umidade variando de 9 a $11 \%$. Os fatores de emissão médios ( $\mathrm{g} / \mathrm{kg}$ de biomassa seca queimada) foram 1,565 \pm 128 para $\mathrm{CO}_{2} \mathrm{e}$ $50,3 \pm 17,1$ para CO. Se compararmos com o trabalho realizado por França et al. (2012), podemos observar que o fator de emissão de $\mathrm{CO}_{2}$, um dos principais gases causadores do efeito estufa, é maior na combustão de biomassa florestal do que na de cana-de-açúcar.

Para o monitoramento de poluentes gasosos confinados em dutos é fundamental uma amostragem representativa, bem como a garantia de que os dados obtidos a partir de cada fonte de emissão sejam diretamente comparáveis a um padrão conhecido. No Brasil, há a 
Resolução no 382/06, estabelecida pelo Conselho Nacional do Meio Ambiente (CONAMA), que fixa os limites de emissão para fontes fixas de geração de combustão, ou seja, para processos industriais de geração de calor utilizando diversas biomassas. O CONAMA também estabelece através da Resolução no 03/90, os padrões nacionais de qualidade do ar. Neste trabalho, comparamos os resultados obtidos com ambas as resoluções.

Para compreender a combustão da biomassa, é importante avaliar as propriedades desta, as quais determinam seu comportamento como um combustível para a combustão. Propriedades que influenciam incluem a estrutura anatômica e os caminhos para a circulação de umidade, teor de umidade, densidade específica, holocelulose e lignina (Demirbas et al., 2005). Williams et al. (2012), destacaram a importância da análise química na caracterização de materiais lignocelulósicos e na predição de outras propriedades, tais como poder calorífico. Descreveram ainda que o poder calorífico superior (PCS) é amplamente explicado pelo teor de lignina. No entanto, não correlaciona-se tão bem com outros parâmetros do combustível, como material volátil e carbono fixo, porque esses parâmetros são fortemente influenciados pelo teor de cinzas e taxa de aquecimento.

Neste contexto, e com o grande incentivo do uso da cana-de-açúcar como combustível industrial, vê-se a importância de se avaliar as características deste combustível tanto como suas propriedades químicas, sua eficiência no processo de combustão, bem como a quantificação dos poluentes emitidos.

\section{OBJETIVOS}

Este trabalho teve como objetivos a quantificação e amostragem dos traços gasosos dos gases $\mathrm{CO}, \mathrm{CO}_{2}$ e $\mathrm{NO}_{\mathrm{X}}$ emitidos em tempo real de queima do bagaço de cana-de-açúcar utilizado como combustível industrial e a realização da análise química do referido combustível.

\section{MATERIAIS E MÉTODOS}

\subsection{Preparação e caracterização das amostras}

Foram coletados cerca de $50 \mathrm{~kg}$ de bagaço de cana-de-açúcar, provenientes da Destilaria Iracema, situada na cidade de Itaí, interior de São Paulo. Posteriormente, o bagaço permaneceu em espaço coberto e ventilado para que secasse ao ar ambiente.

Para a caracterização química, uma amostra da biomassa foi processada em moinho Wiley, para obtenção de serragem. A serragem foi classificada em peneiras de $40(0,420 \mathrm{~mm})$ e 60 mesh $(0,250 \mathrm{~mm})$, sendo utilizado para as análises químicas, o material retido na peneira de 60 mesh, que contém a fração recomendada pelas normas TAPPI T 204 om-97 e TAPPI T 222 om-98. As normas utilizadas para a realização da caracterização química da biomassa foram ABNT NBR 8112/83 (teor de umidade, teor de cinzas, teor de material volátil e teor de carbono fixo), TAPPI T 204 om-97 e TAPPI T 222 om-98 (teor de extrativos, teor de lignina e teor de holocelulose) e ABNT NBR 8633/84 (determinação do poder calorífico). 


\subsection{Descrição do equipamento de queima}

O módulo experimental utilizado para a queima de biomassa é constituído de uma coifa, sistema de alimentação, rosca helicoidal, câmara de combustão, sistema de junção, câmara de aquecimento, duto de amostragem e sistema de controle de poluição do ar. O equipamento foi instalado em série, com junção à caldeira (câmara de combustão), ligação do painel elétrico e motores de forma automatizada. O combustível foi colocado na coifa, sendo posteriormente transportado para a câmara de combustão através da rosca helicoidal. Foi induzida manualmente uma chama no interior da câmara de combustão, iniciando a queima da biomassa. Através do revestimento em refratários, permite-se o isolamento térmico e a maximização da temperatura local. Nos testes de combustão de biomassa, os poluentes gasosos foram amostrados em tempo real durante toda a queima. A entrada de ar para a combustão foi controlada e os fluxos gasosos na chaminé foram avaliados e controlados por válvulas inseridas no setor. Os locais onde foram inseridas as sondas de amostragem e a quantidade de pontos de amostragem no interior do duto foram especificadas segundo a norma CETESB L9.221.

\subsection{Descrição do equipamento de amostragem de gases}

O Eurotron (Green Line) é um analisador de gases que foi utilizado para as análises das emissões gasosas e determinação da composição química dos gases da combustão. Os dados foram coletados em tempo real de amostragem e armazenados. $\mathrm{O}$ equipamento permite a medição da concentração de $\mathrm{SO}_{2}$ e $\mathrm{NO}_{2}$ e a medição de pressão diferencial para medir perdas de carga e velocidade do gás. Determina a composição dos gases $\mathrm{O}_{2}, \mathrm{CO}, \mathrm{CO}_{2}, \mathrm{NOx}$, $\mathrm{NO}_{2}$ e $\mathrm{SO}_{2}$ pela passagem dos mesmos por detector eletroquímico. Está em conformidade com EPA (Environmental Protection Agency).

\section{RESULTADOS E DISCUSSÕES}

\subsection{Caracterização química}

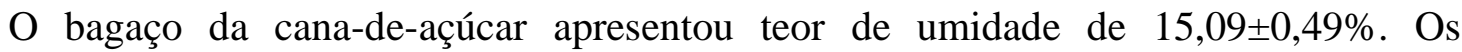
resultados obtidos para caracterização química imediata e energética (poder calorífico superior - PCS) podem ser visualizados na Tabela 1. Os resultados encontrados para caracterização química da parede celular são encontrados na Tabela 2. Nestas tabelas são dispostos também dados da literatura para efeito de comparação.

O teor de umidade encontrado neste trabalho foi maior que o encontrado por Sánchez (2010). Isso explica o fato da obtenção de um valor menor de PCS em relação ao outro autor, pois quanto menor a umidade, melhor a queima do combustível. Além disso, menor poder calorífico resulta em maior teor de carbono fixo e menor teor de materiais voláteis. Os resultados obtidos neste trabalho estão de acordo com estas relações.

Telmo e Lousada (2011) realizaram a análise química de espécies tropicais e obtiveram maior teor de lignina que a biomassa estudada neste trabalho. Consequentemente, o poder calorífico também foi maior. Segundo os autores, essa relação se deve ao fato de que a lignina 
é rica em carbono e hidrogênio, que são os principais elementos que produzem calor. Os extrativos também influenciam no poder calorífico, uma vez que possuem alto valor de aquecimento. Portanto, espécies com maior teor de lignina e extrativos terão melhor poder de queima, gerando mais energia.

Tabela 1 - Composição (\%) e PCS (J/g) encontrados neste trabalho e na literatura.

\begin{tabular}{|c|c|c|c|c|c|c|}
\hline Referência & Biomassa & Umidade & Voláteis & $\begin{array}{c}\text { Carbono } \\
\text { Fixo }\end{array}$ & Cinzas & PCS \\
\hline Este trabalho & $\begin{array}{c}\text { Bagaço de cana-de- } \\
\text { açúcar }\end{array}$ & 15,09 & 75,4 & 16,6 & 7,94 & 16211 \\
\hline $\begin{array}{c}\text { Sánchez } \\
\text { (2010) }\end{array}$ & $\begin{array}{c}\text { Bagaço de cana-de- } \\
\text { açúcar }\end{array}$ & 6,4 & 86,4 & 9,2 & 4,4 & 16700 \\
\hline
\end{tabular}

Tabela 2 - Composição química (\%) da parede celular do bagaço da cana-de-açúcar.

\begin{tabular}{|c|c|c|c|c|}
\hline Referência & Biomassa & Extrativos & Lignina & Holocelulose \\
\hline Este trabalho & $\begin{array}{c}\text { Bagaço de cana-de- } \\
\text { açúcar }\end{array}$ & $1,717 \pm 0,25 \%$ & $25,55 \pm 2,01 \%$ & $73,07 \pm 1,76 \%$ \\
\hline $\begin{array}{c}\text { Telmo e Lousada } \\
(\mathbf{2 0 1 1})\end{array}$ & Espécies tropicais & $14,20 \pm 2,80$ & $37,10 \pm 3,67$ & 61,3 \\
\hline
\end{tabular}

\subsection{Testes experimentais}

A Figura 1 mostra as concentrações de $\mathrm{CO}(\mathrm{ppm})$ emitidas com a queima de bagaço de cana-de-açúcar. As condições da biomassa como teor de umidade (\%) e poder calorífico superior (J/g) são as mesmas descritas no item 4.1.

A maior concentração de CO foi obtida quando o combustível estava na fase de incandescência no processo de combustão e a concentração média do mesmo apresentada durante a queima foi de $122 \mathrm{ppm}$. Este valor é cerca de 3,5 vezes a concentração permitida pelos padrões primário e secundário de qualidade do ar, estabelecidos pelo CONAMA através da Resolução Conama $\mathrm{n}^{\circ}$ 03/90, que é de 35 ppm por hora de amostragem. O valor obtido também ultrapassa drasticamente o limite máximo de emissão de $\mathrm{CO}$ para fontes fixas estabelecido pela Resolução Conama $n^{\circ}$ 436/11, que é de 1,7 ppm. A última atualização das recomendações da Organização Mundial da Saúde (OMS) em 2005, a respeito das concentrações ambientais de poluentes atmosféricos, estabeleceu que o limite ideal de concentração de CO para 1 hora de amostragem é de $30 \mathrm{mg} / \mathrm{m}^{3}$, equivalente a $26,25 \mathrm{ppm}$, limite também drasticamente ultrapassado durante o experimento.

O valor médio de concentração de $\mathrm{CO}$ encontrado neste experimento também ultrapassou o valor máximo de emissão permitido pela legislação federal dos EUA, que estabelece padrões de qualidade do ar para diversos poluentes atmosféricos. Para um tempo de amostragem de 1h, a concentração permitida é de $35 \mathrm{ppm}$, a qual não deve ser 
ultrapassada mais de uma vez ao ano. Este resultado é extremamente prejudicial à saúde, tendo em vista que, de acordo com Téllez (2006), o monóxido de carbono altera a curva de dissociação da hemoglobina, formando no sangue uma substância denominada carboxihemoglobina, a qual dificulta o transporte do oxigênio para os tecidos e células do organismo.

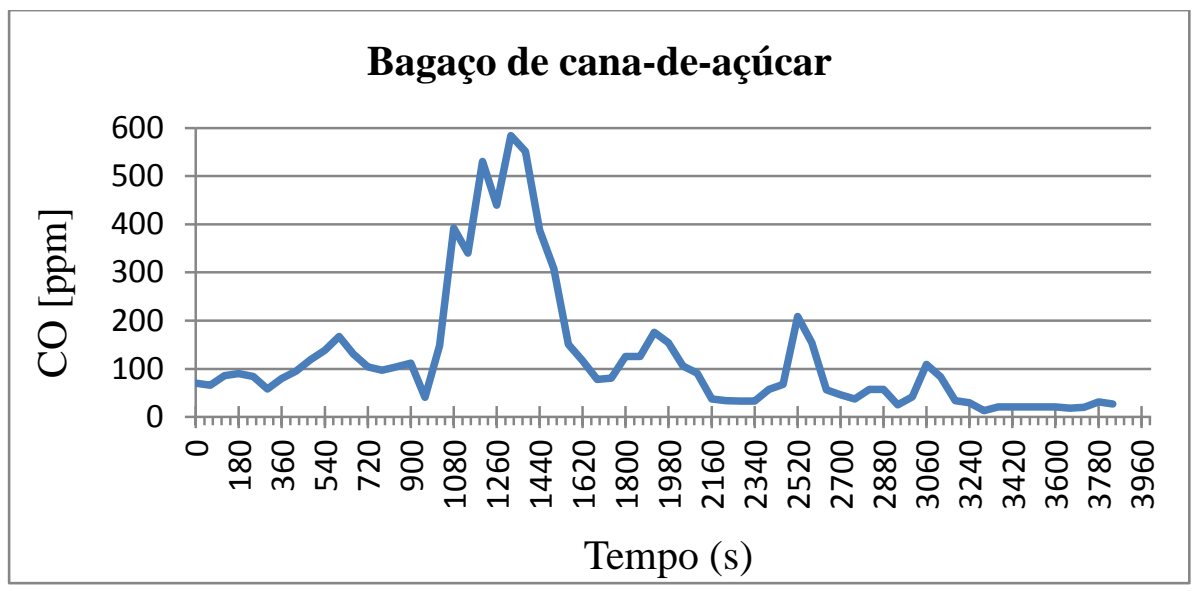

Figura 1 - Concentração de CO em função do tempo de queima.

As Figuras 2 e 3 trazem, respectivamente, as concentrações de $\mathrm{NOx}(\mathrm{ppm})$ e $\mathrm{CO}_{2}(\%)$ emitidas durante a queima da biomassa.

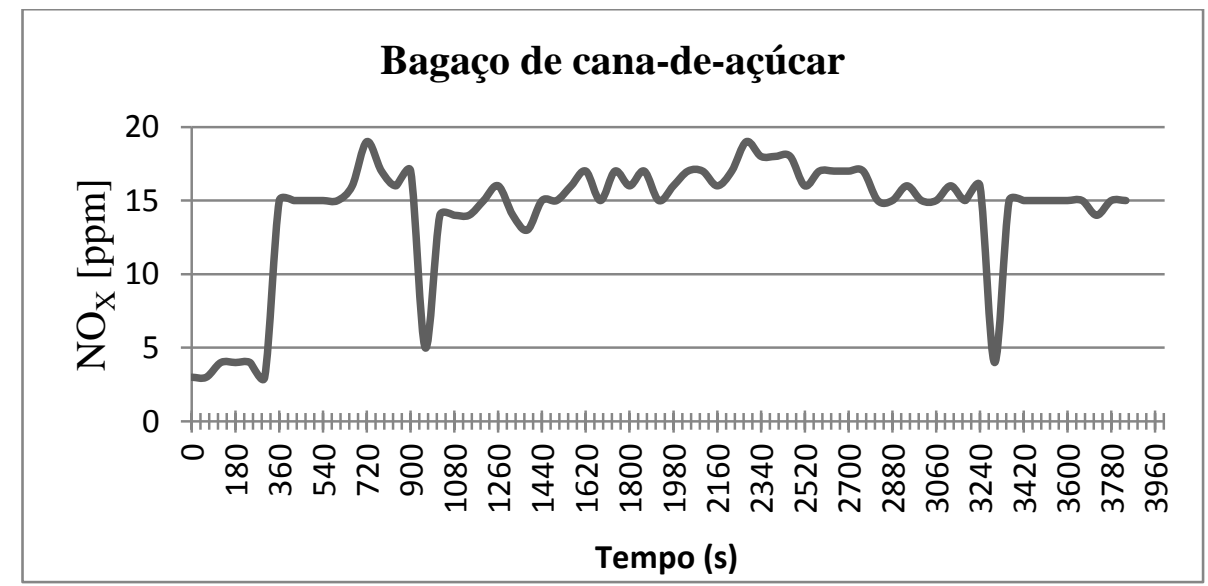

Figura 2 - Concentração de $\mathrm{NO}_{\mathrm{x}}$ em função do tempo de queima.

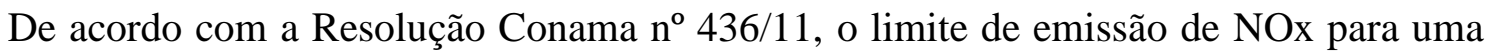
potência de até $50 \mathrm{MW}$ não é aplicável. Entretanto, na legislação federal dos EUA, o limite de concentração de $\mathrm{NO}_{2}$ durante 1 hora de amostragem equivale a $0,1 \mathrm{ppm}$. A média de concentração obtida neste experimento foi de $13,7 \mathrm{ppm}$.

Em relação ao $\mathrm{CO}_{2}$, não foi encontrada nenhuma resolução que estabelecesse limites para o mesmo. Isto evidencia a necessidade da melhoria da normatização dos limites de 
emissões para os gases confinados no interior de dutos.

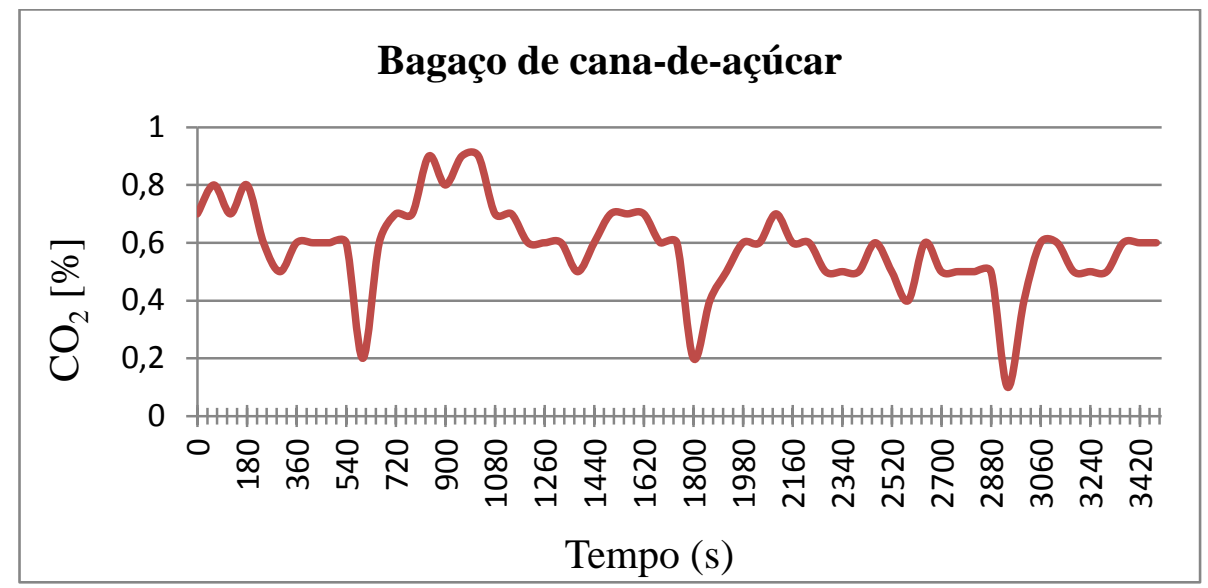

Figura 3 - Concentração de $\mathrm{CO}_{2}$ em função do tempo de queima.

\section{CONCLUSÕES}

Os resultados das análises químicas realizadas estão de acordo com a literatura. As poucas variações observadas são decorrentes das divergências entre as condições da matéria prima. Em relação às emissões de poluentes atmosféricos, todos os limites estabelecidos pelas legislações consultadas foram ultrapassados. Constatou-se também que existem poucos trabalhos na literatura sobre emissões provenientes da combustão controlada em laboratório do bagaço de cana-de-açúcar. Uma vez que a utilização desta biomassa como forma de geração de energia e de substituição dos combustíveis fósseis é crescente no Brasil, trabalhos como este se tornam imprescindíveis para a investigação dos processos atmosféricos, auxiliando no controle das emissões para constante atualização e adequação dos padrões ambientais estabelecidos.

\section{AGRADECIMENTOS}

À FAPESP - Fundação de Amparo à Pesquisa do Estado de São Paulo - pela bolsa concedida (processo 2013/03892-0) e pelo financiamento dos equipamentos utilizados nesta pesquisa (processo 08/04490-4), e à Universidade Estadual Paulista "Júlio de Mesquita Filho" - UNESP, Campus de Itapeva, pelo apoio institucional.

\section{REFERÊNCIAS BIBLIOGRÁFICAS}

ABNT, Associação Brasileira de Normas Técnicas. NBR 8112: Carvão vegetal - Análise imediata, 1983. 
ABNT, Associação Brasileira de Normas Técnicas. NBR 8633: Carvão vegetal Determinação do poder calorífico, 1984.

BLASI, C. D. Modeling chemical and physical processes of wood and biomass pyrolysis. Elsevier: Progress in energy and combustion science, Napoli, p.47-90, 07 dez. 2006.

CARVALHO Jr, J. A.; LACAVA, P. T.. Emissões em processos de combustão. São Paulo: Editora da Unesp, 2003. 137 p.

CETESB. L9.221: Dutos e chaminés de fontes estacionárias. Determinação dos pontos de amostragem, 1990.

Conselho Nacional do Meio Ambiente (Brasil). Resoluções do Conama: Resoluções vigentes publicadas entre setembro de 1984 e janeiro de 2012. Ministério do Meio Ambiente. Brasília: MMA, 2012. $1126 \mathrm{p}$.

COSTA, A. C. A. da; PEREIRA Jr, N.; ARANDA, D. A. G. The situation of biofuels in Brazil: New generation technologies. Elsevier: Renewable and Sustainable Energy Reviews, Rio de Janeiro, p.3041-3049, 20 jul. 2010.

FRANÇA, D. de A.; LONGO, K. M.; NETO, T. G. S.; SANTOS, J. C.; FREITAS, S. R.; RUDORFF, B. F. T.; CORTEZ, E. V.; ANSELMO, E.; CARVALHO Jr, J. A. Pre-Harvest Sugarcane Burning: Determination of Emission Factors through Laboratory Measurements. Atmosphere, São José Dos Campos, p.164-180, 15 fev. 2012.

HOOGWIJK, M.; FAAIJ, A.; BROEK, R. van den.; BERNDES, G.; GIELEN, D.; TURKENBURG, W. Exploration of the ranges of the global potential of biomass for energy. Pergamon: Biomass and Bioenergy, Utrecht, p.119-133, 06 dez. 2002.

Ministério da Agricultura. Cana-de-açúcar. Disponível em: < http://www.agricultura.gov.br/vegetal/culturas/cana-de-acucar>. Acesso em 10 abr. 2014.

NGUYEN, T. L. T.; HERMANSEN, J. E.; SAGISAKA, M. Fossil energy savings potential of sugar cane bio-energy systems. Elsevier: Applied Energy, Tjele, p.S132-S139, 20 maio 2009.

SÂNCHEZ, C. G. (Org.). Tecnologia da gaseificação de biomassa. Campinas: Editora Átomo, 2010.

SANTANA, E.; CUNHA, K. B.; FERREIRA, A. L.; ZAMBONI, A. Padrões de qualidade do ar: experiência comparada Brasil, EUA e União Européia. Instituto de Energia e Meio Ambiente. São Paulo: 2012. Disponível em: < http://www.mma.gov.br/port/conama/processos/C1CB3034/Estudo_Padroes_Qualidade_Ar.p df $>$. Acesso em 25 de fevereiro de 2014.

SOARES NETO, T. G.; CARVALHO JR, J. A.; CORTEZ, E. V.; AZEVEDO, R. G.; OLIVEIRA, R. A.; FIDALGO, W. R. R.; SANTOS, J. C. Laboratory evaluation of Amazon forest biomass burning emissions. Atmospheric Environment, v. 45, p. 7455-7461, 2011.

TAPPI, Technical Association of the Pulp and Paper Industry. T 204: Solvent extractives of wood and pulp, 1997.

TAPPI, Technical Association of the Pulp and Paper Industry. T 222: Acid-insoluble lignin in wood and pulp, 1998.

TÉLLEZ, J.; RODRÍGUEZ, A.; FAJARDO, A. Contaminación por Monóxido de Carbono: un Problema de Salud Ambiental. Salud Publica, Colombia, v. 8, p.108-117, 09 fev. 2006.

TELMO, C.; LOUSADA, J. The explained variation by lignin and extractive contents on higher heating value of wood. Biomass and Bioenergy, v. 35, n. 5, p. 1663-1667, maio 2011.

WILLIAMS, A.; JONES, J. M.; MA, L.; POURKASHANIAN, M. Pollutants from the combustion of solid biomass fuels. Progress in Energy and Combustion Science, v. 38, n. 2, p. 113-137, abr 2012. 